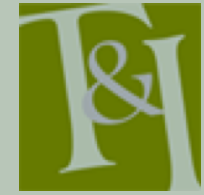

The International Journal for Translation \& Interpreting Research trans-int.org

\title{
Speech-language pathologists' collaboration with interpreters: Results of a current survey in California
}

\section{Terry Irvine Saenz}

California State University, Fullerton

tsaenz@fullerton.edu

\section{Henriette W. Langdon}

San José State University Professor Emerita

henriette.langdon@sjsu.edu

DOI: 10.12807/ti.111201.2019.a03

\begin{abstract}
One of the challenges of bilingual speech and language assessment, intervention, and conferencing is the effective collaboration with interpreters in such interpreted interactions when the professional does not share the same spoken language with the client. A survey of California speech-language pathologists who were members of the California SpeechLanguage-Hearing Association (CSHA) was performed to obtain information on their training to collaborate with, experiences with, and opinions of interpreters. In addition, these professionals were surveyed about the training of the interpreters and suggestions for improvement in interpreted interactions. Findings from 229 participants indicated that: (a) Most of the speech-language pathologists had had instruction, either through university coursework and/or postgraduate presentations, about collaborating with interpreters; (b) Generally, the speech-language pathologists were satisfied with the quality of interpretation/translation; (c) Most interpreters had been trained by their work of employment and/or the speech-language pathologists; but (c) Most of the speech-language pathologists had had to work with family or family friend interpreters at some point, including some who had had to work with family members who were minors.
\end{abstract}

Keywords: speech-language pathologists, speech and language therapists, interpreters in the schools, speech-language assessment and intervention

\section{Introduction}

The purpose of this paper is two-fold. One is to inform readers about the need to recruit and hire interpreters, including ones who are trained in working in special education, specifically to collaborate with speech-language pathologists who must assess English Language Learners in their primary language in the public schools, as mandated by U.S. federal law. The second purpose is to present the results of a survey that was carried out with members of the California Speech-LanguageHearing Association (CSHA).

The U.S. Census Bureau (2015a) recently detailed the hundreds of languages that individuals in the United States speak at home, with a total of 60 million individuals over five years of age (some $21 \%$ of the population) speaking a language other than English in the home. Over 350 languages are spoken, including 150 different Native North American languages. The languages most frequently spoken include Spanish, languages of Chinese (of which there are Mandarin, Cantonese, Guan, Yue, Chan, Min and several others which are 
mutually unintelligible), Tagalog, Vietnamese, French, Korean, and German, all with over one million individuals over five years of age who speak those languages at home (U.S. Census Bureau, 2015a). The use of Spanish far exceeds the use of any other language, with fully $62 \%$ of speakers of languages other than English in the home over five years of age using Spanish (U.S. Census Bureau, 2015b). Between 1990 and 2013, the percentage of those who reported not speaking English very well grew from 14 million to 25.1 million, with almost $9 \%$ of the United States population over five years of age reportedly speaking English less than very well. (U.S. Census Bureau, 2015b).

In the last decade, the number of languages other than English (LOTEs) spoken in California has increased to 207. Californians who spoke a language other than English at home in 2009-2013 included $43.7 \%$ of the state, while $19.4 \%$ of Californians reported that they spoke English less than very well during that period (U.S. Census Bureau, 2015c). The top 10 languages other than English spoken in the state are: Spanish (65.8\% of LOTE speakers), Tagalog $(5.0 \%)$, Vietnamese (3.4\%), Korean (2.4\%), Cantonese (1.5\%), Mandarin (1.4\%), Armenian (1.3\%), Persian (Farsi) (1.3\%), Arabic (1.0\%), and Russian (1.0\%) (U.S. Census Bureau, 2015a).

The current percentage of speech-language pathologists and audiologists in the American Speech-Language-Hearing Association (ASHA) who report they are able to provide services in a language other than English is 7\% (or approximately 11,8000 of a total membership of 179,692), and of those, $63 \%$ are speakers of Spanish. However, the report does not state what languages are represented by the remaining 27\% (ASHA, 2017). Consequently, when assessing individuals who speak languages other than English, most speech-language pathologists must work with interpreters - something which is mandated by special education law in the United States such as the Individuals with Disabilities Education Act (2004).

Although the importance of assessing children in their first language is clearly stated, the methodology for doing so is not specified. No official guidelines have been written for interpreters who work in special education. However, for a child whose proficiency in English is still emerging or is limited, special education laws in the United States specify that assessments should always be "provided and administered in the child's native language or other mode of communication and in the form most likely to yield accurate information on what the child knows and can do academically, developmentally, and functionally" (Individuals with Disabilities Education Act, 2004, Section 300.304(c)(1)(ii)).

To summarize, there is a great variety of languages spoken in the United States. With one in seven residents born overseas, and one in eleven reportedly speaking English less than very well (U.S. Census Bureau, 2014, 2015a), there is a need to provide interpreting and translation services when speakers of these languages require speech-language pathology and/or audiology services. Speechlanguage pathologists and audiologists who work with these linguistically diverse populations need to work effectively with interpreters in the provision of clinical services. The demand for clinical services in various languages far exceeds the supply. Therefore, the need for interpreters in speech-language pathology has never been greater, and interpreters play many crucial roles in an interpreted interaction. Training for interpreters is additionally highly variable in the United States, from formal training programs to no formal training at all.

According to the California Healthcare Interpreting Association (2012), there are four main roles that an interpreter can play within an interpreted interaction: message converter, message clarifier, cultural clarifier, and patient (client) advocate. Interpreters can potentially play more than one role during an 
interpreted interaction (Isaac, 2002). As message converter, the interpreter listens to both speakers and observes body language, converting the message's meaning from one language to another without unnecessary additions, deletions, or changes in meaning (California Healthcare Interpreting Association, 2012). As message clarifier, the interpreter may assist the speaker of an unfamiliar concept to restate it or describe it in a simpler way (California Healthcare Interpreting Association, 2012). As cultural clarifier, the interpreter assists individuals confused by cultural differences by helping clients or speech-language pathologists explain unfamiliar cultural concepts to each other (California Healthcare Interpreting Association, 2012). As a patient advocate, an interpreter can provide information about linguistically appropriate services that are available or suggest that a family be given an interpreter for follow-up appointments (California Healthcare Interpreting Association, 2012). However, this role is not allowed in all countries and may be specific to the California Healthcare Interpreting Association.

\section{Surveys of speech-language pathologists}

Given the significant number of individuals that speak languages other than English, not only in California but the entire United States, it is somewhat surprising that only a few surveys have been published researching how speechlanguage pathologists collaborate with interpreters as part of their practices with bilingual/bicultural individuals. The authors found seven surveys asking speechlanguage pathologists who work primarily in the public school setting about their needs in working with interpreters and their training in working /collaborating with these individuals as well as the efficacy of the process. Dates of publication spanned over 10 years from 2003 (Kritikos) to 2012 (D'Souza, Kay-Raining Bird, \& Deacon; Guiberson \& Atkins, Williams \& McLeod). The researchers surveyed a variable number of speech-language pathologists working primarily in public school settings; the studies ranged from 110 participants (Caesar \& Kohler, 2007) to over 1700 (Roseberry-McKibbin, Brice \& Hanlon, 2005). Questions asked of participants were of typical personal data such as number of years in the field and location of employment as well as the speech-language pathologists' proficiency in another language; if the speech-language pathologists had received training in working with interpreters and how they had gained skills and knowledge in this area; whether they felt competent in differentiating a language disorder from a difference in bilingual students; and if they had access to interpreters.

Kritikos (2003) found that 55\% of her speech-language pathologist respondents in the United States, most of whom worked in a school setting, reported speaking or understanding another language than English. Only 20\% reported preservice academic training in collaborating with interpreters, while $25 \%$ had inservice training on this topic. Forty-four percent of the respondents reported a lack of availability of interpreters who spoke the clients' languages. When reporting personal efficacy in the assessment of a client in the presence of an interpreter, a minimum of $72 \%$ of respondents reported feeling not competent or only somewhat competent. In addition, $92 \%$ or greater responded that most speech-language pathologists were not competent or only somewhat competent, even with the assistance of an interpreter, to assess an individual's language development in a language the speech-language pathologists did not speak.

Hammer, Detwiler, Detwiler, Blood, and Qualls (2004), in a study of practices of school-based speech-language pathologists in working with Spanishspeaking bilingual children in the United States, found that approximately $25 \%$ had received preservice instruction on working with interpreters, while over one 
third desired training on working with them. At the same time, the speechlanguage pathologists were 'somewhat confident' to 'confident' in collaborating with interpreters.

Roseberry-McKibbin, Brice, and O'Hanlon (2005), in a study of schoolbased speech-language pathologists in the United States, found that, similar to the findings of Hammer et al. (2004), 38\% of respondents had taken no preservice course in serving bilingual students. Forty-nine percent had taken part of a course, and almost $13 \%$ had taken a whole course. More recent graduates had received more training at the university level than older graduates. Forty-three percent of respondents cited "lack of interpreters who speak the necessary languages to provide services" (p. 55) as occurring very frequently or frequently. Similarly, $29 \%$ of respondents cited "difficulty distinguishing a language difference from a language disorder" (p. 55) as occurring very frequently or frequently. Forty-seven percent of respondents were extremely interested or quite interested in participating in continuing education training regarding working with interpreters.

In Caesar and Kohler's (2007) survey of school-based speech-language pathologists in Michigan, 28\% of respondents agreed that their graduate education was adequate in terms of theoretical knowledge, with only $11 \%$ perceiving their practical training to be adequate. Forty-eight percent reported using interpreters' support in the assessment process when evaluating bilingual children, and only $53 \%$ indicated the consistent use of assessment in the native language.

In Guiberson and Atkins' survey (2012) of Colorado primarily school-based speech-language pathologists, $21 \%$ had completed coursework involving information on working with interpreters, and $38 \%$ had received continuing education on that topic. Fifty-five percent reported that a challenge was the lack of interpreters and translators. Sixty percent indicated that they worked with interpreters to assess and treat culturally/linguistically diverse clients, with most using a professional interpreter or school personnel and only $14 \%$ reporting working with a family member or friend of the client. Fifty-one percent reported that they were competent in evaluating or providing therapy to bilingual or multilingual clients, and only $25 \%$ reported that they felt competent in evaluating a child's language development working with an interpreter.

A Canadian survey of speech-language pathologists (D'Souza, Kay-Raining Bird \& Deacon, 2012) included $78 \%$ of respondents who had knowledge of more than one language. Twenty-four percent of those working with linguistically diverse clients had not had training to work with such clients. Fifteen percent did not have access to interpreters, and $25 \%$ did not have access to bilingual speechlanguage pathologists. In contrast, the speech-language pathologists who had access to training, interpreters, and bilingual speech-language pathologists and used their services always or frequently were $42 \%, 42 \%$, and $25 \%$, respectively. Fifty-five percent of respondents reported assessing and treating individuals in only the languages they spoke.

In an Australian survey of speech-language pathologists (Williams \& McLeod, 2012), 76\% reported that their university training had not adequately prepared them for working with families from multilingual backgrounds. Fiftyone percent of respondents who worked with multilingual children reported assessing their articulation/phonology without assistance from others, while $66 \%$ conducted language assessments with others, including interpreters provided by the workplace, family members, other speech-language pathologists, other professionals, and community members.

The studies listed above reported several problems: 1) lack of confidence in working with interpreters (Guiberson \& Atkins, 2012; Kritikos, 2003), with the exception of Hammer et al. (2004); 2) lack of availability of interpreters 
(Guiberson \& Atkins, 2012; Kritikos, 2003; Roseberry-McKibbin et al., 2005); and lack of preservice training and/or continuing education in working with interpreters (Guiberson \& Atkins, 2012; Hammer et al., 2004; Kritikos, 2003; Williams \& McLeod, 2012). Additionally, some surveys indicated that respondents did not use the services of interpreters when assessing bilingual children (Caesar \& Kohler, 2007; Guiberson \& Atkins, 2012; Williams \& McLeod, 2012). Based upon the results of these surveys, some speech-language pathologists experienced a lack of training and confidence in working with interpreters and would have benefitted from further training and information in effectively collaborating with them.

\subsection{Collaboration during assessment}

Several articles and chapters have discussed preferred practices in speechlanguage pathologists collaborating with interpreters in assessment conducted with students (Barnett, 1989; Isaac, 2001, 2002, 2005), but actual studies of interpreted interactions are relatively rare with younger populations. There is more information on the assessment process using the services of an interpreter with older patients. In a study of interpreter-mediated aphasia assessments, Roger and Code (2011) found that interpreter-mediated assessments were vulnerable to problems with content validity, which could occur during the administration of a test item or at the time the aphasic client's response was reported back to the speech-language pathologist. Specifically, the interpretation of test items from English to another language was not always equivalent in length and complexity, which inevitably affected the results. At times, items of increasing complexity were simplified, due in part to differences in the structure of the two languages. In other cases, interpreters attempted to preserve semantic content, rather than the syntax of utterances. On occasions, interpreters paraphrased utterances that they were supposed to repeat.

Content validity at the point of reporting was sometimes threatened in several ways (Roger \& Code, 2011). First, interpreters expanded or edited utterances of the clients by filling in gaps. Second, interpreters sometimes asked the clients clarifying questions, and the full sequence of what was said was not relayed to the speech-language pathologist. Finally, interpreters had choices of how to produce utterances of the clients with aphasia for the speech-language pathologists, and the speech-language pathologists might not realize that there were cross-linguistic differences and regard the interpreters' renditions as literal interpretations. Rogers and Code (2011) discussed the importance of a briefing with interpreters before testing to improve assessment, but also stated the importance of speech-language pathologists remaining realistic about what interpreters could provide.

In a study of interpreting and the assessment of confrontation-naming by a client with aphasia, Kambanaros and Steenbrugge (2004) found that the majority of the client's responses were phonologically related to Greek target words but that the interpreter initially did not report these relationships and merely translated the meanings of the Greek words. Consequently, the monolingual speechlanguage pathologist, who was relying on the interpreter's translated responses, thought initially that the responses were semantic paraphasias. Some errors were semantically unrelated but phonologically related, such as vraka (underwear) for varka (boat). The phonological relationships were discovered only after the assessment when the monolingual speech-language pathologist and a bilingual speech-language pathologist discussed the errors.

In a study of an assessment of a Samoan-English speaker with bilingual aphasia (Jodache, Howe, \& Siyambalapitiya, 2015), several themes occurred. The process was deemed difficult for all participants, including the client, a family 
member, the speech-language pathologist, and the interpreter. It was perceived as a team process. Additional time and preparation were required for the assessment, and some tasks were deemed culturally inappropriate. The process also required flexibility in modifying tasks during the assessment. There was a level of uncertainty on the part of the speech-language pathologist about the accuracy of the interpretation and the client's comprehension abilities, given that the family member sometimes prompted the client. Finally, the speech-language pathologist found it advantageous to meet with an interpreter before a second assessment session, something she was unable to do before the first session.

In a medical setting, even a certified medical interpreter could need additional training to work with an speech-language pathologist. Typical courses to become a certified medical interpreter in the United States provide an overview of interpreting procedures, which include, among other things, the briefing, interaction, debriefing process, as well as protocols that may be used in a healthcare setting, and specific vocabulary that relates to different systems like neurological, digestive, lymphatic, testing and practice, but no or limited information on speech-language pathology or audiology issues. Therefore, even the interpreter who is certified in a medical setting could need to be specifically trained with a speech-language pathologist.

\subsection{Collaboration during meetings or therapy}

Just as was the case with studies that focus on speech-language pathologists collaborating with interpreters during clients' speech and language assessments, those that specifically address the interaction of speech-language pathologists with parents or clients in meetings or therapy while collaborating with interpreters were few in number (Friedland \& Penn, 2003; Merlini \& Favaron, 2005). In both studies the interpreters were message converters, message clarifiers, and in some cases, cultural clarifiers (CHIA, 2012). However, it must be noted that the interpreters took on these additional roles without the explicit consent or sanction of the speech-language pathologists.

\subsection{Collaboration during special education meetings}

Although there is a lack of research on speech-language pathologist and interpreter interactions in therapy or assessments, there is research literature on meetings with parents whose children were attending special education programs (Cho \& Gannotti, 2005; Davitti, 2013; Klingner \& Harry, 2006; and Lo, 2008a, $2008 \mathrm{~b}$ ). All studies listed contained a number of themes, some of them common either to more than one researcher or to all. In all cases the interpreters appeared to be unfamiliar with and had difficulty interpreting special education terminology. Davitti's (2013) study found that interpreters were functioning as message converters, message clarifiers, and cultural clarifiers, interjecting their own evaluative assessments or intensifying those of the teachers. The Korean and Chinese parents in the Cho and Gannotti and Lo studies reported dissatisfaction with the quality of interpretation provided by the school interpreters, and the studies by Klingner and Harry and those by Lo found that not all of the dialogue in meetings was being interpreted by the interpreters and was being summarized instead.

In conclusion, the review of the studies described above indicated that collaboration with interpreters presented many challenges. Some studies found that the majority of participants did not feel competent assessing individuals with an interpreter (Guiberson \& Atkins, 2012; Kritikos, 2003). Results of other studies pointed out the need for further training in working with interpreters (Caesar \& Kohler, 2007; Hammer et. al, 2005; Roseberry-McKibbin, Brice, \& Hanlon, 2005; 
Williams \& McLeod, 2012). In both studies of speech-language pathologists working with interpreters in assessment (Kambanaros \& Steenbrugge, 2004; Roger \& Code, 2011) as well as intervention or conferencing (Friedland \& Penn, 2003; Merlini \& Favaron, 2005), difficulties were identified in the accuracy of interpretation. Similarly, in studies of special education meetings, the interpreter's lack of knowledge of special education terminology was an issue (Cho \& Gannotti, 2005; Klingner \& Harry, 2006; Lo, 2008a, 2008b). In many cases (Cho \& Gannotti, 2005; Lo, 2008a, 2008b), parents were dissatisfied with the quality of the interpretation of school interpreters. All of these findings are of concern, particularly as speech-language pathologists are the professionals who determine if individuals have true speech-language disorders that are present in each of their languages or if they merely have speech-language differences due to their acquiring a second language. Misdiagnosis of an individual's speech-language proficiency in all of his/her languages can have far-reaching implications, as an individual may be mistakenly diagnosed with a speech-language disorder and given unneeded therapy, or alternatively may not receive needed speech-language services. Key to appropriate diagnosis is effective collaboration with interpreters to determine individuals' speech-language competency in all languages spoken.

\section{Survey of California speech-language pathologists}

The existing research concerning the collaboration between speech-language pathologists and interpreters when assessing bilingual students who might have language/learning difficulties led the authors to design a survey of California speech-language pathologists to obtain further information about the training for and experiences with working with interpreters.

The questions that were asked in conducting this survey were the following:

1. What were the characteristics of the clients seen by the participants in this survey?

2. In which ways did the speech-language pathologists collaborate with interpreters?

3. How much and what type of training did the participants practicing in California report receiving in working with interpreters?

4. How much and what type of training did the interpreters they work with receive in interpretation and translation? In addition, how did they rate the training of the interpreters they have worked with?

5. What type of training did they wish to receive for themselves and the interpreters to continue improving their skills in assessing clients whose first language is other than English?

\section{Method}

The California Speech-Language-Hearing Association (CSHA) commissioned a Task Force on Collaborating with Interpreters and Translators with the first and second coauthor as cochairs and three other individuals as members of the task force. The task force was commissioned to write a position paper on best practices of speech-language pathologists and audiologists collaborating with interpreters in California. As part of their commission, they developed a survey to be sent to all California Speech-Language-Hearing Association (CSHA) members who were speech-language pathologists or audiologists to determine what were common 
practices across the state. The coauthors developed a set of questions in consultation with one another, and the members of the task force revised them based on questions from earlier surveys of professional practices of speechlanguage pathologists with bilingual/bicultural individuals. Two outside consultants with experience with surveys also reviewed the survey and made suggestions for revisions, which were incorporated into the final survey.

The final survey was converted into the Qualtrics survey program at California State University, Fullerton. The survey was then submitted to the institutional review boards (IRB) of California State University, Fullerton and San José State University and was approved for distribution by both. The survey included a total of 32 questions. The questionnaire took 15 to 20 minutes to complete.

The survey was sent as a link in an email from CSHA to speech-language pathologist and audiologist members inviting them to complete the survey three times over a two-week period, so that potential participants would have an opportunity to complete the survey once. Participants clicked upon the link and completed the survey. The Qualtrics survey program then totaled the responses and provided percentages. The link to the survey was sent to 3743 speechlanguage pathologists and audiologists in California, of whom 253 individuals completed the survey. However, only three audiologists and one speech-language pathologist/audiologist completed the survey, and a number of individuals did not indicate which profession(s) they belonged to. In addition, 17 individuals stated that they did not currently work with clients, but some in that category completed the survey although respondents were directed to only continue if they currently worked with clients. Consequently, the Qualtrics program was used to filter out the responses of individuals who did not state that they were only speechlanguage pathologists and/or did not currently work with clients. The data from the remaining respondents, 229 individuals who were all speech-language pathologists working with clients, was used in the analysis. This represented approximately $6 \%$ of the total of surveys mailed to CSHA members.

\section{Participants}

A majority (165, i.e. $72.05 \%)$ of the sample reported their primary work setting to be in the public schools. The next largest group was those who worked in private practice (31, i.e. $13.54 \%$ ). The number of years of experience as a speechlanguage pathologist varied, with the largest group, over one fourth (63, i.e. $27.51 \%$ ), having 31 or more years of experience. The largest group of respondents was non-Latino Caucasian, with 158 (70.54\%) respondents. An additional 16 (7.14\%) did not identify their race/ethnicity. Both Hispanic/Latino and Asian American/Pacific Islander respondents each constituted 19 (8.48\%) of the sample (see Table 1).

\section{Results}

Sixty-five percent $(65 \%)$ of the respondents stated they had 0-25 clients on their caseload (28.51\%), 72 respondents stated that they had 26-50 clients $(31.58 \%)$, and 91 respondents stated that they had over 50 clients (39.91\%).

The majority of clients were in the school-age range, with the largest number of respondents serving clients in preschool (131 responses, i.e. 57.21\% respondents) and/or elementary school (148 responses, i.e. $64.63 \%$ respondents). 
The percentage of respondents' caseloads that were English Language Learners varied, although it is notable that almost one third of the sample had English Language Learners for over $50 \%$ of their caseload (see Table 2).

Table 1. Primary work setting, number of years of experience, and race/ethnicity of survey respondents

\begin{tabular}{|c|c|c|}
\hline & $\begin{array}{l}\text { Number of } \\
\text { Responses }\end{array}$ & $\begin{array}{l}\text { Percentage of } \\
\text { Respondents }\end{array}$ \\
\hline \multicolumn{3}{|l|}{ Work Setting } \\
\hline Public Schools & 165 & 72.05 \\
\hline Private Practice & 31 & 13.54 \\
\hline University & 9 & 3.93 \\
\hline Medical Pediatric Facility & 8 & 3.49 \\
\hline Acute Inpatient Facility & 8 & 3.49 \\
\hline Inpatient Rehabilitation Facility & 7 & 3.06 \\
\hline Outpatient Rehabilitation Facility & 7 & 3.06 \\
\hline Skilled Nursing Facility & 6 & 2.62 \\
\hline Private/Non-Public Schools & 4 & 1.75 \\
\hline Other & 10 & 3.93 \\
\hline \multicolumn{3}{|l|}{ Number of Years of Experience } \\
\hline $0-5$ years & 41 & 17.90 \\
\hline $6-10$ years & 35 & 15.28 \\
\hline $11-15$ years & 30 & 13.10 \\
\hline $16-20$ years & 25 & 10.92 \\
\hline $21-25$ years & 23 & 10.04 \\
\hline $26-30$ years & 12 & 5.24 \\
\hline 31 years or more & 63 & 27.51 \\
\hline \multicolumn{3}{|l|}{ Race/Ethnicity } \\
\hline African American & 5 & 2.23 \\
\hline Asian American/Pacific Islander & 19 & 8.48 \\
\hline Hispanic/Latino & 19 & 8.48 \\
\hline Native American & 1 & 0.45 \\
\hline Non-Latino Caucasian & 158 & 70.54 \\
\hline Mixed Race/Ethnicity & 6 & 2.68 \\
\hline Other* & 16 & 7.14 \\
\hline
\end{tabular}

* Six respondents $(2.68 \%$ of the total) in this category identified themselves as Caucasian, White, or Euro-American.

Table 2. Ages of clients and percentage of caseloads that were English Language Learner students

\begin{tabular}{|l|r|r|}
\hline Age of Clients & $\begin{array}{c}\text { Number of } \\
\text { Responses }\end{array}$ & $\begin{array}{c}\text { Percentage of } \\
\text { Respondents }\end{array}$ \\
Infant & 33 & 14.41 \\
Preschool & 131 & 57.21 \\
Elementary & 148 & 64.63 \\
Middle School/Junior High School & 83 & 36.24 \\
High School & 74 & 32.31 \\
Adult & 53 & 23.14 \\
Geriatric Adult & 35 & 15.28 \\
\hline Percentage of caseload that were & & \\
English language learners & 83 & 36.56 \\
0-25\% & 73 & 32.16 \\
16-50\% & 35 & 15.42 \\
$51-75 \%$ & 36 & 15.86 \\
$76->$ & & \\
\hline
\end{tabular}


Almost $20 \%$ of respondents stated that they provided bilingual services themselves (45, i.e. 19.74\%). A variety of languages were cited, including American Sign Language; over one fourth of the respondents (14, i.e. $25.45 \%)$ who reported providing bilingual services stated that they were native speakers of Spanish. Similarly, one half of the individuals providing bilingual services (28, i.e. $50.91 \%$ ) stated that they had acquired Spanish (see Table 3).

Table 3. List of languages provided by respondents

\begin{tabular}{|l|r|r|}
\hline Language & $\begin{array}{r}\text { Number of } \\
\text { Responses }\end{array}$ & $\begin{array}{c}\text { Percentage of } \\
\text { Respondents }\end{array}$ \\
\hline Native Speaker & 14 & \\
Spanish & 2 & 25.45 \\
Filipino/Tagalog & 2 & 3.64 \\
American Sign Language & 1 & 3.64 \\
Farsi & 1 & 1.82 \\
Greek & 1 & 1.82 \\
Hebrew & 1 & 1.82 \\
isiZulu & 1 & 1.82 \\
Mandarin & 1 & 1.82 \\
Polish & & 1.82 \\
\hline Non-native Speaker & 28 & \\
Spanish & 5 & 50.91 \\
English & & 9.09 \\
American Sign Language/ Sign & 4 & \\
Language & 1 & 7.27 \\
Afrikaans & 1 & 1.82 \\
Dutch & 1 & 1.82 \\
French & 1 & 1.82 \\
German & 1 & 1.82 \\
Yiddish & 1.82 \\
\hline
\end{tabular}

Respondents were asked about the percentage of non-English-speaking clients for whom they needed to collaborate with an interpreter, relative to their total caseload. The differences between languages were marked. Respondents were more likely to need the services of an interpreter with the Spanish-speaking population than with other populations. Almost half of the respondents needed to collaborate with a Spanish-speaking interpreter for $11 \%$ or more of their caseload (102, i.e. $45.13 \%)$. By comparison, in the large majority of other languages, only $1-10 \%$ (if that much) of the caseload's individuals required working with an interpreter. However, the percentage of speech-language pathologists who collaborated with interpreters at least some of the time varied across languages, with $62(28.57 \%), 61(27.98 \%)$, and 52 respondents $(23.96 \%)$ reporting some level of collaboration with interpreters for Tagalog, Vietnamese, and Arabicspeaking clients respectively. A variety of other languages were cited by the respondents as needing interpreters, most prominently American Sign Language/sign language (9), Armenian (6), Farsi, (4), and German (4) as the most frequently cited other languages (see Table 4 ). 
Table 4. Percentage of non-English-speaking clients using services where an interpreter was needed

\begin{tabular}{|c|c|c|}
\hline $\begin{array}{l}\text { Non-English Languages and Ranges of } \\
\text { Percentages }\end{array}$ & $\begin{array}{l}\text { Number of } \\
\text { Responses }\end{array}$ & $\begin{array}{l}\text { Percentage of } \\
\text { Respondents }\end{array}$ \\
\hline \multicolumn{3}{|l|}{ Spanish } \\
\hline None & 37 & 16.37 \\
\hline $1-10 \%$ & 87 & 38.50 \\
\hline $11-25 \%$ & 38 & 16.81 \\
\hline $26-50 \%$ & 36 & 15.93 \\
\hline $51-75 \%$ & 15 & 6.64 \\
\hline $76 \%$ or greater & 13 & 5.75 \\
\hline \multicolumn{3}{|l|}{ Arabic } \\
\hline None & 165 & 76.04 \\
\hline $1-10 \%$ & 47 & 21.66 \\
\hline $11-25 \%$ & 1 & 0.46 \\
\hline $26-50 \%$ & 3 & 1.38 \\
\hline $51-75 \%$ & 0 & 0.00 \\
\hline $76 \%$ or greater & 1 & 0.46 \\
\hline \multicolumn{3}{|l|}{ Cantonese } \\
\hline None & 183 & 84.72 \\
\hline $1-10 \%$ & 30 & 13.89 \\
\hline $11-25 \%$ & 1 & 0.46 \\
\hline $26-50 \%$ & 1 & 0.46 \\
\hline $51-75 \%$ & 1 & 0.46 \\
\hline \multicolumn{3}{|l|}{ One or more Eastern Indian languages } \\
\hline None & 164 & 80.39 \\
\hline $1-10 \%$ & 34 & 16.67 \\
\hline \multicolumn{3}{|l|}{ Hmong } \\
\hline None & 189 & 89.57 \\
\hline $1-10 \%$ & 21 & 9.95 \\
\hline $11-25 \%$ & 1 & 0.47 \\
\hline \multicolumn{3}{|l|}{ Korean } \\
\hline None & 172 & 81.13 \\
\hline $1-10 \%$ & 37 & 17.45 \\
\hline $11-25 \%$ & 1 & 0.47 \\
\hline $26-50 \%$ & 1 & 0.47 \\
\hline $51-75 \%$ & 0 & 0.00 \\
\hline $76 \%$ or greater & 1 & 0.47 \\
\hline \multicolumn{3}{|l|}{ Mandarin } \\
\hline None & 179 & 82.11 \\
\hline $1-10 \%$ & 35 & 16.06 \\
\hline $11-25 \%$ & 2 & 0.92 \\
\hline $26-50 \%$ & 1 & 0.46 \\
\hline $51-75 \%$ & 1 & 0.46 \\
\hline \multicolumn{3}{|l|}{ Native American Languages } \\
\hline None & 196 & 95.61 \\
\hline $1-10 \%$ & 5 & 2.44 \\
\hline $11-25 \%$ & 1 & 0.49 \\
\hline \multicolumn{3}{|l|}{ Russian } \\
\hline None & 179 & 84.04 \\
\hline $1-10 \%$ & 30 & 14.08 \\
\hline $11-25 \%$ & 2 & 0.94 \\
\hline $26-50 \%$ & 1 & 0.47 \\
\hline $51-75 \%$ & 0 & 0.00 \\
\hline $76 \%$ or greater & 1 & 0.47 \\
\hline \multicolumn{3}{|l|}{ Tagalog } \\
\hline None & 155 & 71.43 \\
\hline $1-10 \%$ & 57 & 26.27 \\
\hline $11-25 \%$ & 2 & 0.92 \\
\hline $26-50 \%$ & 2 & 0.92 \\
\hline $51-75 \%$ & 1 & 0.46 \\
\hline \multicolumn{3}{|l|}{ Vietnamese } \\
\hline None & 157 & 72.02 \\
\hline $1-10 \%$ & 54 & 24.77 \\
\hline $11-25 \%$ & 4 & 1.83 \\
\hline $26-50 \%$ & 3 & 1.38 \\
\hline
\end{tabular}


The next section of the survey focused on experiences with interpreters. Over half worked with interpreters for interviews and conferences from 1 to $25 \%$ of the time (129, i.e. $57.08 \%$ ), as did over one half for assessments (137, i.e. 59.83\%) (see Table 5).

Table 5. How frequently speech-language pathologists worked with interpreters in different contexts

\begin{tabular}{|l|r|r|}
\hline $\begin{array}{l}\text { Non-English Languages and Ranges } \\
\text { of Percentages }\end{array}$ & $\begin{array}{c}\text { Number of } \\
\text { Incidences }\end{array}$ & $\begin{array}{c}\text { Percentage of } \\
\text { Incidences }\end{array}$ \\
\hline $\begin{array}{l}\text { Interviews/Conferences } \\
\text { Never }\end{array}$ & 21 & \\
1-25\% of the time & 129 & 9.29 \\
$26-50 \%$ of the time & 43 & 19.08 \\
$51-75 \%$ of the time & 18 & 7.03 \\
Over 75\% of the time & 15 & 6.64 \\
\hline Assessments & 35 & \\
Never & 137 & 15.28 \\
1-25\% of the time & 29 & 59.83 \\
$26-50 \%$ of the time & 14 & 12.66 \\
$51-75 \%$ of the time & 14 & 6.11 \\
Over 75\% of the time & & 6.11 \\
\hline Therapy & 131 & \\
Never & 81 & 57.21 \\
1-25\% of the time & 11 & 35.37 \\
$26-50 \%$ of the time & 3 & 4.80 \\
$51-75 \%$ of the time & 3 & 1.31 \\
Over $75 \%$ of the time & & 1.31 \\
\hline
\end{tabular}

Less than $10 \%$ of respondents (21, i.e. $9.29 \%)$ never worked with interpreters for interviews and conferences, as did less than $20 \%$ (35, i.e. $15.28 \%$ ) for assessments. In contrast, over one half never worked with interpreters for therapy (131, i.e. $57.21 \%$ ), and over a third of respondents worked with interpreters for therapy $1-25 \%$ of the time $(81$, i.e. $35.57 \%$ ).

Interpreters had performed a wide variety of services for the respondents, including strict interpretation (190, i.e. 89.20\%), explanations/support of vocabulary/ specific terms (149, i.e. $69.95 \%)$, cultural support (91, i.e. $42.72 \%)$, interpretation of nonverbal exchanges (62, i.e. $29.11 \%$ ), and other duties (17, i.e. $7.98 \%$ ). Their most frequently other cited services for speech-language pathologists included their collaboration during IEP meetings and assessments.

There were a variety of means by which speech-language pathologists learned to work with interpreters, and the majority of respondents felt at least somewhat well trained when they began collaborating with interpreters (see Table $6)$.

However, the interest in further training was great, as almost two thirds of the respondents (147, i.e. $65.92 \%$ ) indicated interest in obtaining further training in collaborating with interpreters, compared to approximately one third (76, i.e. $34.08 \%$ ) who did not indicate interest.

Respondents indicated that they collaborated with a variety of types of interpreters, most notably bilingual aides or assistants employed in their work setting $(169$, i.e. $74.45 \%)$, trained interpreters employed by their work setting (166, i.e. $73.13 \%)$, and bilingual adult family members or friends of the family (135, i.e. $59.47 \%$ ) (see Table 7). 
Table 6. Means by which speech-language pathologists learned to work with interpreters, and degree to which they felt trained to work with interpreters

\begin{tabular}{|l|r|c|}
\hline & $\begin{array}{c}\text { Number of } \\
\text { Responses }\end{array}$ & $\begin{array}{c}\text { Percentage of } \\
\text { Respondents }\end{array}$ \\
\hline Means & 105 & 46.88 \\
Undergraduate/graduate programs & 95 & 42.41 \\
Inservices in work settings & 101 & 45.09 \\
Seminars/workshops at the local, & \\
state and/or national level & 85 & 37.95 \\
Relevant books and/or journals & 57 & 25.45 \\
$\quad$ No formal training & 56 & \\
\hline Degree to which felt trained & 70 & 25.11 \\
Felt very well trained & 55 & 24.39 \\
Felt somewhat well trained & & \\
Felt neither well trained nor poorly & & 10.31 \\
$\quad$ trained & 23 & 8.52 \\
Felt somewhat poorly trained & 19 & \\
$\quad$ trained & & \\
\hline
\end{tabular}

Table 7. Types of interpreters with whom speech-language pathologists have worked

\begin{tabular}{|l|c|c|}
\hline Type of Interpreter & $\begin{array}{c}\text { Number of } \\
\text { Responses }\end{array}$ & $\begin{array}{c}\text { Percentage of } \\
\text { Respondents }\end{array}$ \\
\hline $\begin{array}{c}\text { Bilingual aides or assistants } \\
\text { employed by work setting } \\
\text { Trained professional interpreters } \\
\text { employed by work setting }\end{array}$ & 169 & 74.45 \\
$\begin{array}{c}\text { Bilingual adult family members or } \\
\text { friends of the family }\end{array}$ & 166 & 73.13 \\
$\begin{array}{l}\text { Bilingual speech-language } \\
\text { pathologist or audiologist }\end{array}$ & 135 & 59.47 \\
$\begin{array}{l}\text { Bilingual professionals in other fields } \\
\text { Volunteer bilingual interpreters }\end{array}$ & 93 & 55.95 \\
$\begin{array}{l}\text { Bilingual family members who are } \\
\text { minors }\end{array}$ & 64 & 40.97 \\
$\quad \begin{array}{l}\text { Telephone interpreters } \\
\text { Video conferencing interpreters }\end{array}$ & 62 & 28.19 \\
Other & 51 & 27.31 \\
\hline
\end{tabular}

Over half of the speech-language pathologists indicated that they thought that their interpreters were 'very well trained' (44, i.e. 19.30\%) or 'somewhat well trained' $(98$, i.e. $42.98 \%)$. The remainder found their interpreters to be 'neither well trained nor poorly trained' $(59$, i.e. $25.88 \%)$, 'somewhat poorly trained' (19, i.e. $8.33 \%$ ), or 'very poorly trained or not at all trained' (8, i.e. $3.51 \%)$. Fifteen (14.71\%) reported over forty hours of formal training of interpreters by their institution, while $23(22.55 \%)$ indicated that their interpreters had received less than forty hours of formal training from the institution. Twenty-seven (26.47\%) had provided training to the interpreters, while over one third of the participants (37, i.e. $36.27 \%$ ) stated that their interpreters had no formal training by their institution.

Almost $60 \%$ of respondents (131, i.e. 59.01\%) reported following the recommended briefing, interaction, and debriefing (BID) process with interpreters before and after interpreted interactions, while $30(13.51 \%)$ only met with the 
interpreters before, 9 (4.05\%) only met with them afterward, and $52(23.42 \%)$ did not meet with them before or after interpreted interactions.

There were a number of suggestions to improve the quality of interpretation/translation, most notably providing formal or more training for interpreters (143 responses, i.e. $65.30 \%$ respondents) and more formal training for speech-language pathologists and audiologists (126, i.e. 57.53\%) (See Table 8).

Table 8. Suggestions to improve the quality of interpretation/translation at the speech-language pathologists' work facilities

\begin{tabular}{|l|c|c|}
\hline Suggestion & $\begin{array}{c}\text { Number of } \\
\text { Responses }\end{array}$ & $\begin{array}{c}\text { Percentage of } \\
\text { Respondents }\end{array}$ \\
\hline $\begin{array}{l}\text { Provide Formal or More Training in } \\
\text { Interpretation/Translation for Individuals } \\
\text { Who Function as Interpreters }\end{array}$ & 143 & 65.30 \\
Provide More Formal Training in Working \\
with Interpreters to Speech-Language \\
$\begin{array}{l}\text { Pathologists } \\
\text { Hire Professional Interpreters }\end{array}$ & 126 & 57.53 \\
$\begin{array}{l}\text { Avoid Using Family Members or Friends of } \\
\text { the Family for Interpreters }\end{array}$ & 82 & 37.44 \\
Provide More Formal Training in Working \\
$\quad \begin{array}{l}\text { with Interpreters to Other Professionals } \\
\text { and Staff }\end{array}$ & 80 & 36.53 \\
Other & 79 & 36.07 \\
\hline
\end{tabular}

Finally, almost $60 \%(135$, i.e. $59.47 \%)$ indicated that there were instances in which they needed to work with an interpreter but could not, in contrast to those who had not had that difficulty $(92$, i.e. $40.53 \%)$. A number of reasons were given, with the most common being that the speech-language pathologist could not find one (95, i.e. $69.34 \%$ ) (see Table 9).

Table 9. Reasons why speech-language pathologists could not work with an interpreter when needed

\begin{tabular}{|l|c|c|}
\hline Reason & $\begin{array}{c}\text { Number of } \\
\text { Responses }\end{array}$ & $\begin{array}{c}\text { Percentage of } \\
\text { Respondents }\end{array}$ \\
\hline Could Not Find One & 95 & 69.34 \\
Interpreters Were Poorly Trained & 36 & 26.28 \\
Did Not Get the Assistance That Was & 32 & 23.36 \\
Needed from the Interpreter & & \\
Employer Did Not Want to Pay for One & 22 & 16.06 \\
Did Not Know How to Train the Interpreter & 7 & 5.11 \\
Other* & 26 & 18.98 \\
\hline
\end{tabular}

* Nine $(6.57 \%)$ in the "Other" category stated that there was a schedule conflict or one was unavailable.

\section{Discussion}

\subsection{Overview of results}

The findings of the present survey have some commonalities and differences with the previously cited surveys.

\subsubsection{Characteristics of the clients seen by participants in this survey}

In the present survey, $72 \%$ of the respondents stated that they worked in a publicschool setting, but a substantial minority worked in other settings, in contrast to 
the findings of Caesar and Kohler (2007), Hammer et al. (2004), and RoseberryMcKibbin, Brice, and O'Hanlon (2005), who surveyed only school-based speechlanguage pathologists. The percentage of speech-language pathologists' caseloads that were English Language Learners was quite high. Only 37\% reported a percentage of $0-25 \%$, but $32 \%$ and $31 \%$ reported a caseload of $26-50 \%$ and $51 \%$ or more, respectively of English language learners.

The need to collaborate with an interpreter for Spanish-speaking clients was marked in the sample: $28 \%$ needed to collaborate with Spanish-speaking interpreters for over one fourth of their caseload, and only $16 \%$ did not need to collaborate with Spanish-speaking interpreters at all. In contrast, the percentages of those who needed to collaborate with interpreters on behalf of English Language Learner students who spoke other languages were as follows: Tagalog, 29\%; Vietnamese, 28\%; Arabic, 24\%; Korean, 19\%; Mandarin, 18\%; Russian, 16\%; Cantonese, 15\%; Hmong, 10\%; and Native American languages, 4\%. Although Spanish was by far the most common language, other languages were also needed for some of the speech-language pathologists.

\subsubsection{Manner of collaboration with interpreters}

The speech-language pathologists in this sample collaborated extensively with interpreters in working with their caseload, most frequently for interviews and conferences, with only $9 \%$ reporting no collaboration and $34 \%$ collaborating $26 \%$ or more of the time. Similarly, only $15 \%$ of the respondents never collaborated with interpreters in assessment, and almost $25 \%$ collaborated with interpreters $26 \%$ or more of the time. This was in contrast to Caesar and Kohler's (2007) survey, in which only $53 \%$ of respondents indicated the consistent use of assessment in the native language, and $70 \%$ reported working with interpreters, and Guiberson and Atkins' survey (2012), in which 60\% indicated that they worked with interpreters in assessment and therapy. In contrast to the large numbers working with interpreters for interviews/conferences or assessments, $57 \%$ of the present survey sample never collaborated with interpreters for therapy, and only $7 \%$ collaborated with interpreters for therapy more than $25 \%$ of the time. Consequently, English Language Learner students were undergoing bilingual assessments, but English was typically the language used in therapy. It is possible that the variation in the number of speech-language pathologists who collaborated with interpreters depended on the language in demand in a given public school setting (for example, there might have been more interpreters available who spoke Spanish as compared to another language like Tagalog or Mandarin). In addition, the emphasis upon instruction in English in California public schools at the time of the survey could have influenced the lack of collaboration with interpreters in therapy.

Respondents collaborated with interpreters in a variety of ways. As expected, $89 \%$ worked with interpreters for strict interpretation. However, $70 \%$ of speechlanguage pathologists reported that interpreters provided explanations, support of vocabulary, and specific terms, thus acting as message clarifiers (CHIA, 2012). In addition, $43 \%$ collaborated with interpreters for cultural support, and $29 \%$ worked with interpreters on the interpretation of nonverbal exchanges, acting as cultural clarifiers (CHIA, 2012). Consequently, interpreters were providing far more than strict interpretation in their interactions with clients, families, and speechlanguage pathologists. 
7.1.3 Type of training received by participants practicing in California in working with interpreters

Many of the respondents had obtained information on collaborating with interpreters from a variety of sources. Forty-seven percent $(47 \%)$ had had such information provided in undergraduate and/or graduate programs, in contrast to Kritikos' (2003) and Guiberson and Atkins' (2012) samples, in which approximately $20 \%$ had such academic training, and Hammer et al.'s (2004) sample, in which approximately $25 \%$ had received training. The high percentage of speech-language pathologists in the current study receiving academic information on working with interpreters is especially notable, as $43 \%$ of the respondents had more than twenty years of experience in the field, a finding that would suggest that such training had been offered at academic institutions for an extensive period of time. Still, $25 \%$ reported receiving no formal training on the topic.

Respondents were generally positive about their training to collaborate with interpreters prior to working with them, with $57 \%$ stating that they felt 'very well or somewhat well trained' to collaborate with them, similar to Hammer et al.'s (2004) findings that her respondents felt somewhat confident when working with interpreters. However, Kritikos (2003) reported that over $72 \%$ of her respondents felt 'not competent or only somewhat competent' in working with interpreters in assessment, similar to the $25 \%$ of Guiberson and Atkins' (2012) respondents that felt competent in evaluating a child's language development when working with an interpreter. In part, this could be because California is a very culturally/linguistically diverse state, and speech-language pathologists may have more experience working with interpreters than professionals in other states. Nevertheless, almost two thirds of participants $(66 \%)$ in the current survey were interested in receiving additional information on the topic, compared with the $41 \%$ of respondents in Roseberry-McKibbin et al.'s (2005) survey who wished for continuing education, again perhaps reflecting the large multilingual/multicultural population in the state.

\subsubsection{How did speech-language pathologists rate the training of interpreters?}

Slightly over $73 \%$ of respondents had worked with trained professional interpreters employed by the work setting. Twenty-two percent $(22 \%)$ had worked with telephone interpreters, and $7 \%$ had video conferenced with interpreters. A number of researchers have recommended that professionals collaborate with only trained interpreters (Flores, 2005; Flores et al., 2003; Karliner et al., 2007; Lo, 2008a). An impressive 56\% of respondents in the present study had worked with bilingual speech-language pathologists or audiologists, while $41 \%$ had worked with bilingual professionals in other fields - all individuals who would be familiar with technical terminology in the two working languages, as recommended by Cho and Gannotti (2005), Klingner and Harry (2006), and Lo (2008a). However, speech-language pathologists collaborated with other types of interpreters, and it was unclear to what degree and/or whether these had been trained by their workplace or the speech-language pathologist. Seventy-four percent $(74 \%)$ of respondents reported working with bilingual aides or assistants employed in the work setting, $28 \%$ with volunteer interpreters, and $59 \%$ with adult family members or friends of the family. Some researchers have reported that using the services of interpreters who are not sufficiently trained, including friends or family friends of the clients, is a substantially less satisfactory solution than working with professional interpreters (Flores, 2005; Karliner et al., 2007). Of particular concern was the fact that $27 \%$ of the sample had worked with a 
bilingual family member who was a minor, a collaboration that is not considered best practice (ASHA, n.d.; Mennen \& Stansfield, 2006).

In spite of the wide range of interpreters, the majority of respondents found the interpreters that they had worked with well trained. Sixty-two percent of the sample stated that their interpreters were either 'very well trained' or 'somewhat well trained', whereas only $12 \%$ reported that their interpreters were 'somewhat poorly trained' or 'very poorly trained or not at all trained'. These opinions were in spite of the fact that the majority of the sample had at one point worked with interpreters who were family members. The training of the interpreters varied, with $37 \%$ reporting some degree of training by the workplace, and $26 \%$ indicating that they had trained the interpreters. Only 36\% indicated no training of interpreters by their workplace. Fifty-nine percent indicated that they followed the recommended BID process by briefing and debriefing their interpreters before and after their interpreted interactions. In contrast, only $23 \%$ did not meet with the interpreter before or after the interpreted interaction, indicating that most were familiar with and followed recommended procedures.

7.1.5 What type of training did they wish to receive for themselves and the interpreters?

The participants had a number of suggestions to improve the quality of interpretation and translation at their work setting. Further training for individuals working as interpreters $(65 \%)$ and for speech-language pathologists and audiologists on the topic (58\%) were the options that obtained the most support. Interestingly enough, only $37 \%$ suggested hiring professional interpreters, providing more formal training to other bilingual professionals and staff $(36 \%)$, or avoiding working with family members of family friends as interpreters $(37 \%)$. This was in contrast to the strong suggestion by some researchers to use the services of professional interpreters and not family members (Flores, 2005; Karliner et al., 2007; Lo, 2008a). Some indicated that the interpreters were poorly trained $(26 \%)$ or that they did not get the assistance they needed from the interpreter $(23 \%)$. Consequently, although participants indicated general satisfaction with their interpreters, there were times when the experience was unsatisfactory.

\subsection{Limitations}

There were several limitations to this study. First, the sample was geographically limited to speech-language pathologists who were members of the California Speech-Language-Hearing Association (CSHA). The demographics of California are considerably more culturally/linguistically diverse than in many other places, and the data reflected that diversity in survey participants and clients. Secondly, several of the participants may have self-selected themselves on the basis of their interest in and experience with the topic of interpreters and translators, as 229 was a relatively small percentage of the CSHA membership, and the proportion of survey participants who were bilingual was larger than that for speech-language pathologists in the state as a whole. Consequently, this sample may have been more familiar with diversity and clinical practice with culturally/linguistically diverse populations than a representative sample of the speech-language pathologist population of the United States or even in California. Thirdly, the majority of respondents were speech-language pathologists, and the voices of audiologists were not "heard" in this survey. Fourthly, this is a survey which solely rates the participants' perceptions, and some other means may have provided more objective responses - for example, if additional data were collected randomly by surveying at least 10 to $15 \%$ of the sample for further information 
(interviewing the respondents through personal meetings and observations of their actual practices). Fifthly, it would have been more objective to determine if the results obtained were more characteristic of particular regions from California or if they represented various regions, because the numbers of English Language Learner students are not equally distributed across the state. Specifically, the Los Angeles Unified School District is the largest in the nation that has English language learner students, with the San Diego Unified, Santa Ana Unified and Fresno Unified school districts following it in decreasing order (Batalova \& McHugh, 2010).

\subsection{Clinical implications}

There were some concerns with clinical implications. The majority of respondents had worked at some time with adult family members or family friends, and about $25 \%$ had worked with family members who were minors as interpreters. Working with minors as interpreters is not considered best practice (ASHA, no date; Mennen \& Stansfield, 2006). In addition, a majority of participants were unable to find an interpreter at least one time, and one fourth stated that they had difficulty in working with the interpreter. Participants recommended additional training for interpreters as well as speech-language pathologists to improve interpreted interactions. This is consistent with best practices in the field of speech-language pathology as well as other fields. However, there seems to be an overall trend in this survey and in other previous ones conducted on this topic: the interpreters who collaborate with speech-language pathologists in school districts do not have a unified education on the best practice for working with English language learner students and their families. It is recommended that they receive more specific training and certification just like interpreters in other fields, such as medical, judicial/court or international conferencing. Receiving more formal education and certification will ensure a stronger collaboration with speech-language pathologists and audiologists. Concurrently, professionals in communication disorders should receive formal and ongoing training on best practices in collaborating with interpreters. This is a need that is observed not only in California, but throughout the nation and the world.

\subsection{Work in progress}

The two authors of this paper, with the assistance of three other task force members, have utilized the results presented here to draft a Position Paper on Collaboration of Speech-Language Pathologists with Interpreters and Translators in the Public Schools, which has been approved by the Executive Board of the California Speech-Language Hearing Association (CSHA). The next steps will be to approach legislators to pass a bill to mandate that interpreters in the public schools be certified in working with speech-language pathologists, just as medical, legal or sign interpreters are required to have formal training. There will probably be financial considerations that will need to be taken into account in the process. However, the proper training of interpreters and speech-language pathologists who work with English Language Learner students in the public schools will afford greater assurances that they are equipped for their respective roles. This will in turn enable speech-language pathologists to more adequately and fairly assess and work with English Language Learner students in California, and may possibly even lead to changes thorughout the entire United States. 


\section{References}

American Speech-Language-Hearing Association (no date). Collaborating with interpreters. Retrieved on December 18, 2015 from http://www.asha.org/PRPPrint Template. aspx? folderid $=8589935334$

American Speech-Language-Hearing Association (2017). Demographic profile of ASHA members providing bilingual services. Retrieved from www.asha.org/uploadedFiles/ Demographic-Profile-Bilingual-Spanish-Service-Members.pdf

Barnett, S. (1989). Working with interpreters. In D. Duncan (Ed.), Working with bilingual language disability (pp. 91-112). London, United Kingdom: Chapman and Hall.

Batalova, J., \& McHugh, M. (2010). States and districts with the highest number and share of English language learners. Washington, DC: Migration Policy Institute.

Caesar, L., \& Kohler, P. (2007). The state of school-based bilingual assessment: Actual practice versus recommended guidelines. Language, Speech, and Hearing Services in Schools, 38, 190-200.

California Healthcare Interpreting Association (2012). California standards for healthcare interpreters: Ethical principles, protocols, and guidance on roles and intervention. Retrieved on March 4, 2014 from http://www.chiaonline.org/?page=CHIAStandards

Cho, S.-J., \& Gannotti, M. (2005). Korean-American mothers' perception of professional support in early intervention and special education programs. Journal of Policy and Practice in Intellectual Disabilities, 2, 1-9.

D'Souza, C., Kay-Raining Bird, E., \& Deacon, H. (2012). Survey of Canadian speechlanguage pathology service delivery to linguistically diverse clients. Canadian Journal of Speech-Language Pathology and Audiology, 36, 18-39.

Davitti, E. (2013). Dialogue interpreting as intercultural mediation: Interpreters' use of upgrading moves in parent-teacher meetings. Interpreting, 15, 168-199. doi: 10.1075/intp.15.2.02.dav

Flores, G., Laws, M., Mayo, S., Zuckerman, B., Abreu, M., Medina, L., \& Hardt, E. (2003). Errors in medical interpretation and their potential clinical consequences in pediatric encounters. Pediatrics, 111, 6-14. doi: 10.1542/peds.111.1.6

Flores, G. (2005). The impact of medical interpreter services on the quality of health care: A systematic review. Medical Care Research and Review, 62, 255-299. doi: $10.1177 / 1077558705275416$

Friedland, D., \& Penn, C. (2003). Conversation analysis as a technique for exploring the dynamics of a mediated interview. International Journal of Language and Communication Disorders, 38, 95-111. doi: 10.1080/13682820110116848

Guiberson, M., \& Atkins, J. (2012). Speech-language pathologists' preparation, practices, and perspectives on serving culturally and linguistically diverse children. Communication Disorders Quarterly, 33, 169-180. doi: 10.1177/1525740110384132

Hammer, C., Detwiler, J., Detwiler, J., Blood, G., \& Qualls, C. (2004). Speech-language pathologists' training and confidence in serving Spanish-English bilingual children. Journal of Communication Disorders, 37, 91-108. doi: 10.1016/j.jcomdis.2003.07. 002

Individuals with Disabilities Education Act (2004). PL 108-446, 108th Congress, 20 United States Code (USC) 1400 et seq. Retrieved from https://sites.ed.gov/idea/regs/ $\mathrm{b} / \mathrm{d} / 300.304 / \mathrm{c}$

Isaac, K. (2001). What about linguistic diversity? A different look at multicultural health care. Communication Disorders Quarterly, 22, 110-113.

Isaac, K. (2002). Speech pathology in cultural and linguistic diversity. London, United Kingdom: Whurr Publishers.

Isaac, K. (2005). Managing linguistic diversity in the clinic: Interpreters in speechlanguage pathology. In M. Ball (Ed.), Clinical sociolinguistics (pp. 265-280). Malden, MA: Blackwell Publishing.

Jodache, S., Howe, T., \& Siyambalapitiya, S. (2015). Assessment of a Samoan-English speaker with bilingual aphasia: "It's hard." Aphasiology, 29, 872-888.

Kambanaros, M., \& Steenbrugge, W. (2004). Interpreters and language assessment: Confrontation naming and interpreting. Advances in Speech-Language Pathology, 6, 247-252. doi: 10.1080/14417040400010009U 
Karliner, L., Jacobs, E., Chen, A., \& Mutha, S. (2007). Do professional interpreters improve clinical care for patients with Limited English Proficiency? A systematic review of the literature. Health Services Research, 42, 727-753. doi: 10.1111/j.14756773.2006.00629.x

Klingner, J., \& Harry, B. (2006). The special education referral and decision-making process for English Language Learners: Child Study Team meetings and placement conferences. Teachers College Record, 108, 2247-2281.

Kritikos, E. (2003). Speech-language pathologists' beliefs about language assessment of bilingual/bicultural individuals. American Journal of Speech-Language Pathology, 12, 73-91.

Lo, L. (2008a). Chinese families' level of participation and experiences in IEP meetings. Preventing School Failure, 53, 21-27.

Lo, L. (2008b). Interactions between Chinese parents and special education professionals in IEP meetings: Implications for the education of Chinese immigrant children with disabilities. In G. Li \& L. Wang (Eds.), Model minority myth revisited: An interdisciplinary approach to demystifying Asian American educational experiences (pp. 195-212). Charlotte, NC: Information Age Publishing, Inc.

Mennen, I., \& Stansfield, J. (2006). Speech and language therapy service delivery for bilingual children: A survey of three cities in Great Britain. International Journal of Language and Communication Disorders, 41, 635-652. doi: 10.1080/ 13682820600623911

Merlini, R., \& Favaron, R. (2005). Examining the "voice of interpreting" in speech pathology. Interpreting, 7, 263-302.

Roger, P., \& Code, C. (2011). Lost in translation? Issues of content validity in interpretermediated aphasia assessments. International Journal of Speech-Language Pathology, 13, 61-73.

Roseberry-McKibbin, C., Brice, A., \& O'Hanlon, L. (2005). Serving English language learners in public school settings: A national survey. Language, speech, and hearing services in schools, 36, 48-61.

U.S. Census Bureau (2014, June). English-speaking ability of the foreign-born population in the United States: 2012. Retrieved from http://www.census.gov/newsroom/pressreleases/2014/cb14-105.html

U.S. Census Bureau (2015a, November 3). Census Bureau reports at least 350 languages spoken in U.S. Homes. Retrieved from http://www.census.gov/newsroom/pressreleases/2015/cb15-185.html

U.S. Census Bureau (2015b, October). Table 1. Detailed languages spoken at home and ability to speak English for the population 5 years and over for the United States: 2009-2013. Retrieved from http://www.census.gov/data/tables/2013/demo/200920013-lang-tables.html

U.S. Census Bureau (2015c, October). Table 5. Detailed Languages Spoken at Home and Ability to Speak English for the Population 5 years and Over for California: 200920013. Retrieved from https://www.census.gov/data/tables/2013/demo/2009-2013lang-tables.html

Williams, C., \& McLeod, S. (2012). Speech-language pathologists' assessment and intervention practices with multilingual children (2012). International Journal of Speech-Language Pathology, 14, 292-305. 